\title{
Evaluation of the Biological Activity of Folic Acid-Modified Paclitaxel-Loaded Gold Nanoparticles
}

\author{
Bin $\operatorname{Ren}^{1,2, *}$ \\ Zhong-Chao Cai ${ }^{1} *$ \\ Xue-Jie Zhao' \\ Lin-Song $\mathrm{Li}^{\prime}$ \\ Mei-Xia Zhao (D)
}

'Key Laboratory of Natural Medicine and Immuno-Engineering of Henan Province, Henan University, Jinming Campus, Kaifeng, Henan, 475004, People's Republic of China; ${ }^{2}$ School of Mathematics and Statistics, Henan University, Jinming Campus, Kaifeng, 475004, People's Republic of China

*These authors contributed equally to this work
Correspondence: Mei-Xia Zhao Key Laboratory of Natural Medicine and Immune Engineering of Henan Province, Henan University, Jinming Campus, Kaifeng, Henan, 475004, People's Republic of China

Email zhaomeixia20II@henu.edu.cn
Purpose: Gold nanoparticles (AuNPs) with good physical and biological properties are often used in medicine, diagnostics, food, and similar industries. This paper explored an AuNPs drug delivery system that had good target selectivity for folate-receptor overexpressing cells to induce apoptosis.

Methods: A novel drug delivery system, Au@MPA-PEG-FA-PTX, was developed carrying paclitaxel (PTX) on folic acid (FA) and polyethylene glycol (PEG)-modified AuNPs. The nanomaterial was characterized by transmission electron microscopy (TEM), Fouriertransform infrared spectroscopy (FTIR), and ultraviolet-visible spectroscopy (UV-Vis). Also, the biological activity of the AuNPs drug delivery system was examined using the 3-(4,5-dimethylthiazol-2-yl)-2,5-diphenyltetrazolium bromide (MTT) assay in HL-7702, Hela, SMMC-7721, and HCT-116 cells. Furthermore, apoptotic activity using annexin V-FITC, mitochondrial membrane potential (MMP), and reactive oxygen species (ROS) levels was estimated by flow cytometry and fluorescence microscopy.

Results: $\mathrm{Au} @$ MPA-PEG-FA-PTX exhibited a distinct core-shell structure with a controllable size of $28 \pm 1 \mathrm{~nm}$. Also, the AuNPs maintained good dispersion and spherical shape uniformity before and after modification. The MTT assay revealed good antitumor activity of the Au@MPA-PEG-FA-PTX against the Hela, SMMC-7721, and HCT-116 cells, while Au@MPA-PEG-FA-PTX produced better pharmacological effects than PTX in isolation. Further mechanistic investigation revealed that effective internalization of AuNPs by folate-receptor overexpressing cancer cells induced cell apoptosis through excessive production of intracellular ROS.

Conclusion: The AuNPs drug delivery system showed good target selectivity for folatereceptor overexpressing cancer cells to induce target cell-specific apoptosis. These AuNPs may have great potential as theranostic agents such as in cancer.

Keywords: gold nanoparticles, folic acid, paclitaxel, drug delivery system, apoptosis

\section{Introduction}

Gold nanoparticles (AuNPs), firstly used as a coloring agent, have been in use for a very long time. However, only in the last few decades, these were developed and utilized in various scientific fields, such as medicine, diagnostics, and food. ${ }^{1-4}$ Owing to their good physical and chemical properties, including large surface area and excellent biocompatibility, AuNPs have been explored by a large number of researchers. ${ }^{5-7}$ Especially, AuNPs have gained much attention as nanocarriers for efficient drug targeting and tracking. ${ }^{8-10}$ Importantly, AuNPs can be effectively modified for specific targeting to reduce premature drug release. $^{11-15}$ 
Paclitaxel (PTX), approved by the US FDA in 1992, is a key drug to treat advanced cancer. Particularly, it has been effective against breast and ovarian cancer while also showing good apoptotic effects against other tumor cells. ${ }^{16-19}$ Regrettably, PTX has many toxic side effects such as myelosuppression, neurotoxicity, cardiotoxicity, joint or muscle pain, liver toxicity, and renal toxicity. ${ }^{20-22}$ Moreover, it is sparingly water-soluble and therefore has limited application as an intravenous injection. ${ }^{23}$ Luckily, AuNPs with good water solubility and targeting can reduce the side effects of such drugs and improve their efficacy. ${ }^{24-26}$

Generally, drug administration can be divided into active and passive targeted drug delivery. ${ }^{27-30}$ In active targeting, the drug carrier loaded with small targeting molecules selectively targets the tumor cells and thereby reduces the toxicity side effects. ${ }^{31,32}$ For instance, folic acid (FA), a water-soluble vitamin, can bind to cell membrane folate receptors of the tumor cells. ${ }^{33}$ Notably, these receptors are highly expressed on the tumor cells than normal cells. ${ }^{34}$ Therefore, FA-modified drugs can selectively target the tumor cells. ${ }^{35}$ For example, Zhang et $\mathrm{al}^{36}$ presented a targeted nanoparticle drug delivery, which used polymeric nanoparticles-coated with FA a regioselectively modified alkyne-folate was employed as a model small-molecule ligand to realize the targeting of drug delivery. Besides, it can improve the water solubility of a poorly soluble drug, improving its reach to tumor cells and efficacy. ${ }^{37-42}$

In this study, a drug-loading system Au@MPA-PEG-FAPTX was prepared and evaluated using MTT assay for targeting efficiency. FA modified AuNPs showed improved targeting in a series of cell experiments that estimated apoptosis, mitochondrial membrane potential (MMP), and the levels of intracellular ROS. The modified AuNPs produced better pharmacological effects than the PTX alone.

\section{Materials and Methods \\ Materials}

All reagents and solvents were purchased from commercial suppliers and used without further purification. These were as follows: tetrachloroauric acid trihydrate $\left(\mathrm{AuCl}_{4} \mathrm{H}_{7} \mathrm{O}_{3}\right)$, mercaptopropionic acid (MPA), amino polyethylene glycol $\left(\mathrm{NH}_{2}-\mathrm{PEG}-\mathrm{NH}_{2}, \mathrm{PEG}\right)$, folic acid (FA), paclitaxel (PTX), triethylamine (TEA), N-hydroxysuccinimide (NHS), ethanesulfonic acid (MES), ethylcarbodiimide hydrochloride (EDC), trypsin, fetal bovine serum (Invitrogen Corporation), 1640 medium (Gibco Invitrogen), tetramethylazozolium blue (MTT), Hoechst 33342, propidium iodide
(PI), acridine orange/ethidium bromide (AO/EB), 2',7'dichlorofluorescein diacetate $\left(\mathrm{H}_{2}\right.$ DCF-DA), annexin V-FITC, rhodamine 123 (Rh123), JC-1 (5,5',6,6'tetrachloro-1,1',3,3'-tetraethyl-imidacarbocyanine iodide) and other organic fluorescent dyes (Sigma). The cell lines, HeLa (cervical cancer cell), QSG-7701 (normal liver cell), SMMC-7721 (liver cancer cells), and HCT-116 (colon cancer cells) were purchased from the Chinese Academy of Sciences Shanghai Cell Bank.

\section{Characterization}

Transmission Electron Microscope (TEM): The morphology and size of AuNPs were analyzed by the JEOL JEM200CX, TEM, operating up to $200 \mathrm{kV}$. Samples of the TEM were prepared by dropping nanoparticles solution on the surface of a copper grid coated with amorphous carbon film. Zeta potential measurement: Zeta potential measurements were done at $25{ }^{\circ} \mathrm{C}$ using Nano ZS90 Zeta potential analyzer (Brookhaven). The nanoparticles concentration was $1 \mathrm{mg} / \mathrm{mL}$ in deionized water. UV-Vis absorption spectra: UV-Vis absorption spectra in the region $800-200 \mathrm{~nm}$ and in the temperature range 300-20 $\mathrm{K}$ were recorded in digitized form at $0.5 \mathrm{~nm}$ intervals with a Varian Cary 300 BIO ultraviolet and visible spectrophotometry (UV-Vis) set at $0.5 \mathrm{~nm} / \mathrm{s}$ scan speed, $1 \mathrm{~s}$ integration time, and $0.5 \mathrm{~nm}$ bandwidth. The samples were diluted to a specified concentration (absorbance value is less than 0.1 ) in the corresponding solvents (PBS, pH 7.0 in water, at room temperature). FTIR Spectroscopy: Fourier transform infrared (FTIR) spectra were measured with a NEXUS FTIR spectrometer (Thermo Nicolet Co., Santiago, MA, USA). Samples were placed in a Specac cell with $\mathrm{CaF} 2$ windows and a $0.05 \mathrm{~mm}$ spacer. Spectra in the range $500-4000 \mathrm{~cm}^{-1}$ were registered with 256 scans at $2 \mathrm{~cm}^{-1}$ resolution. Baseline correction was performed by subtracting the solvent + cell spectrum, after appropriate normalization. High content screening (HCS) analysis: The intracellular fluorescence intensity of samples was detected by high content screening (HCS) analysis (Thermo Scientific Cellomics ArrayScan VTI, Cellomics, Pittsburgh, PA). Briefly, after cells were seeded into 96 -well plates at $5 \times 10^{5}$ cells/well for $24 \mathrm{~h}$, cells were treated with samples at specified concentration for specified times, and the cells were stained with different dyes for $30 \mathrm{~min}$, then washed 3 times with PBS. And then the intracellular fluorescence intensity of the samples for $30 \mathrm{~min}$ was detected using HCS. The other instruments used in this study were as 
follows: multi-function microplate reader (BioTek, USA); LCQDECA-XP mass spectrometer (Thermo); fluorescence spectrophotometer (Agilent, USA), and so on.

\section{Synthesis of AuNPs}

$156 \mu \mathrm{L}$ of $150 \mathrm{mM} \mathrm{HAuCl}{ }_{4}$ was dissolved in $80 \mathrm{~mL}$ of triple-distilled water by boiling in the dark for $10 \mathrm{~min}$. Then, sodium citrate solution ( $92 \mathrm{mg}$ dissolved in $3 \mathrm{~mL}$ of triple-distilled water) was injected with stirring while boiling for $30 \mathrm{~min}$. The mixture was cooled at room temperature (RT) and then centrifuged at $8000 \mathrm{rpm}$ for $15 \mathrm{~min}$ to obtain the gold elemental solution. The centrifuged AuNPs were dissolved in $2 \mathrm{~mL}$ of triple-distilled water and stored at $4{ }^{\circ} \mathrm{C}$.

\section{Synthesis of Au@MPA}

The obtained AuNPs were uniformly dissolved in $50 \mathrm{~mL}$ of triple-distilled water in a $100 \mathrm{~mL}$ round bottom flask, and the $\mathrm{pH}$ was adjusted to 11 . Then, the reaction with $3 \mathrm{~mL}$ of $0.01 \mathrm{M}$ MPA ethanol solution was carried out for $2 \mathrm{~h}$. Finally, the mixture was centrifuged at $9000 \mathrm{rpm}$ for 5 min to obtain the MPA coated gold nanoparticles Au@MPA.

\section{Synthesis of Au@MPA-PEG}

$\mathrm{Au} @$ MPA was uniformly dispersed in a $250 \mathrm{~mL}$ round bottom flask, and the solution $\mathrm{pH}$ was adjusted to 6.5 with MES (ethanesulfonic acid, $50 \mathrm{mM})$. Next, EDC (7 mg) and NHS $(10.5 \mathrm{mg})$ were added and mixed by stirring for $30 \mathrm{~min}$. Subsequently, PEG $(20 \mathrm{mg})$ was added and the mixture was stirred for $24 \mathrm{~h}$ at RT. Lastly, the Au@MPAPEG was obtained by centrifugation at $10,000 \mathrm{rpm}$ for 5 min.

\section{Activation of FA}

FA (250 mg) was dissolved in dimethyl sulfoxide (DMSO) $(20 \mathrm{~mL})$ in a $100 \mathrm{~mL}$ round bottom flask, and the mixture was sonicated for $45 \mathrm{~min}$. Subsequently, NHS (225 mg) and dicyclohexylcarbodiimide (DCC) (125 mg) were added to activate the carboxyl group of the FA under nitrogen for $12 \mathrm{~h}$. The mixture was filtered and transferred to a brown flask to store at $4{ }^{\circ} \mathrm{C}$ for further use.

\section{Synthesis of Au@MPA-PEG-FA}

Au@MPA-PEG was added to $20 \mathrm{~mL}$ of triple-distilled water, and the mixture was uniformly dispersed in a $250 \mathrm{~mL}$ round bottom flask. Then, $1 \mathrm{~mL}$ of activated FA was added under $\mathrm{N}_{2}$ protection, while the flask was maintained in a $45{ }^{\circ} \mathrm{C}$ oil bath for $5 \mathrm{~min}$. After $6 \mathrm{~h}$ of the reaction (end of the reaction), the mixture was divided into $5 \mathrm{~mL}$ portions for dialysis in 2000 molecular weight dialysis bags against $500 \mathrm{~mL}$ triple-distilled water using a magnetic stirrer. Water used for dialysis was changed every $6 \mathrm{~h}$ for continuous dialysis for $48 \mathrm{~h}$. After the dialysis, the product was purified by repeated centrifugation at $14,000 \mathrm{rpm}$ for 5 min to obtain the final product Au@MPA-PEG-FA.

\section{Synthesis of Au@MPA-PEG-FA-PTX}

Au@MPA-PEG-FA was dissolved in an appropriate amount of DMSO in a three-necked bottle. Then, $26 \mathrm{mg}$ of PTX was added followed by dropwise addition of triethylamine $(2 \mathrm{mg})$ for $12 \mathrm{~h}$ in a nitrogen protection environment. At the end of the reaction, the solution was centrifuged at $16,000 \mathrm{rpm}$ for $10 \mathrm{~min}$ to obtain the final product Au@MPA-PEG-FA-PTX.

\section{Drug Release in vitro}

5 mg Au@MPA-PEG-FA-PTX in triplicate were added in $5 \mathrm{~mL}$ phosphate buffered saline (PBS) ( $\mathrm{pH} 5.0,6.5,7.4)$ to ultrasonic dissolve, respectively. The above three solutions were transferred to the three dialysis bags, which were immersed in $150 \mathrm{~mL}$ PBS with corresponding $\mathrm{pH}$ values (5.0, 6.5, 7.4). The PBS solution was stirred slowly at $37{ }^{\circ} \mathrm{C}$, and the samples were taken out once at intervals $(1 \mathrm{~h}, 2 \mathrm{~h}, 3 \mathrm{~h}, 4 \mathrm{~h}, 5 \mathrm{~h}, 6 \mathrm{~h}, 7 \mathrm{~h}, 8 \mathrm{~h}, 9 \mathrm{~h}$, and $10 \mathrm{~h}$ ), at the same time, the same amount corresponding to the fresh PBS was added. The absorbance values of the samples were measured using an ultraviolet spectrophotometer, and the cumulative release of the drug was calculated according to the standard curve.

\section{Estimating the Antitumor Activity of AuNPs}

The antitumor activity of the AuNPs was tested against HL-7702, Hela, SMMC-7721, and HCT-116 cells using a modified 3-(4,5-dimethyl-2-thiazolyl)-2,5-diphenyltetrazolium bromide (MTT) method. ${ }^{43}$ AuNPs were tested in different concentrations $(1,3,5,10,15,30 \mu \mathrm{g} / \mathrm{mL})$.

\section{Cell Apoptosis Assay: Annexin V-FITC Staining}

Cell apoptosis was estimated by flow cytometry. Briefly, after $48 \mathrm{~h}$ of treatment with 3, 5,10,15 $\mu \mathrm{g} / \mathrm{mL}$ of Au@MPAPEG-FA-PTX. Hela cells were stained with annexin V-FITC for $10 \mathrm{~min}$ in a cell incubator. Apoptotic cells were detected 
by the FACSCalibur flow cytometer (Becton Dickinson \& Co., Franklin Lakes, NJ). Data were analysed by using BD Cell Quest software. Percentages of live and apoptotic cells were determined on the basis of negative controls obtained by staining controls only with annexin $\mathrm{V}$.

\section{Analysis of MMP}

Hela cells treated with Au@MPA-PEG-FA-PTX (3, 5, $10,15 \mu \mathrm{g} / \mathrm{mL}$ ) for $24 \mathrm{~h}$ at $37{ }^{\circ} \mathrm{C}$ were incubated with $10 \mu \mathrm{g} / \mathrm{mL} \mathrm{JC}-1$ for $10 \mathrm{~min}$ at $37{ }^{\circ} \mathrm{C}$. The cells were subsequently analyzed with a FACSCalibur flow cytometer.

Hela cells treated with Au@MPA-PEG-FA-PTX (3, 5, $10,15 \mu \mathrm{g} / \mathrm{mL}$ ) for $24 \mathrm{~h}$ at $37^{\circ} \mathrm{C}$ were incubated with $5 \mu \mathrm{g} /$ $\mathrm{mL} \mathrm{Rh123}$ for $25 \mathrm{~min}$ at $37^{\circ} \mathrm{C}$, and then Hoechst 33342 was added for $15 \mathrm{~min}$ to avoid light staining.

\section{Measurement of Reactive Oxygen Species (ROS)}

The accumulation of intracellular ROS was estimated using 2',7'-dichlorofluorescein diacetate $\left(\mathrm{H}_{2} \mathrm{DCF}-\mathrm{DA}\right)$. The Hela cells treated with Au@MPA-PEG-FA-PTX samples $(3,5,15 \mu \mathrm{g} / \mathrm{mL})$ for $24 \mathrm{~h}$ were incubated with $50 \mu \mathrm{M}$ of $\mathrm{H}_{2}$ DCF-DA for $25 \mathrm{~min}$ at $37^{\circ} \mathrm{C}$.

\section{The Antitumor Efficacy of Drug Delivery System in vivo}

The animal experiment was carried out in accordance with the guidelines and approval of the Animal Welfare and Use Committees of Henan University to ensure animal welfare during experiments. Healthy female Balb/c mice of 5 weeks old were chosen for establishing a xenograft tumor model to evaluate the efficacy of the drug delivery system in vivo. Briefly, the mice were randomly divided into 3 groups with 5 mice in each group $(n=5)$, and the xenograft tumor model was injected subcutaneously with CT- 26 cells $\left(5 \times 10^{6}\right.$ cells in
$200 \mu \mathrm{L}$ normal saline). When the tumor was grown to $200 \mathrm{~mm}^{3}, 200 \mu \mathrm{L}$ normal saline, free drug PTX $(5 \mathrm{mg} / \mathrm{kg})$ and the AuNPs drug delivery system (Au@MPA-PEG-FAPTX, $5 \mathrm{mg} / \mathrm{kg}$ ) were injected into the Balb/c mice on the $1 \mathrm{st}$, 3rd, 5th, 7th, 9th, 11th, 13th and 15th day. The body weight of the mice and the size of the tumors were measured every other day. The formula for calculating the tumor volume is $\mathrm{V}=\mathrm{W}^{2} \times \mathrm{L} / 2$. Here, $\mathrm{W}$ refers to the shortest diameters of the tumor, $\mathrm{L}$ indicates the longest diameters of the tumor.

\section{Results and Discussion Preparation and Characterization of AuNPs}

First, we prepared the water-soluble AuNP@MPA (Scheme 1). Figure 1A depicts the morphology of AuNP@MPA particles by TEM. The shape of AuNP@MPA was almost spherical having a compact size of $18 \pm 1 \mathrm{~nm}$. Next, AuNP@MPA-PEG and AuNP@MPA-PEG-FA were prepared (Scheme 1). Furthermore, AuNP@MPA-PEG-FA was loaded with the anti-tumor drug PTX to obtain the final product Au@MPA-PEG-FA-PTX with excellent aqueous stability. Also, the morphology of these particles was analyzed by TEM (Figure 1B-D). Morphologically, AuNP@MPAPEG-FA and AuNP@MPA were almost similar, and the average diameter of AuNP@MPA-PEG-FA particles was 28 \pm 1 nm. TEM revealed that after the modification, Au@MPAPEG-FA-PTX particles showed a distinct core-shell structure indicating the successful modification (Figure 1D).

Besides, we tested the change in charge value of these AuNPs. Figure 2 shows that the unmodified AuNPs (Au@MPA) have a negative charge (MPA with negative charge because of the presence of sulfhydryl), and the charge value changed from -25 to +22 after FA modification (FA with positive charge), and then to +31 after PTX loading (PTX with negative charge). This change in charge indicates that the AuNPs were successfully modified. ${ }^{44,45}$

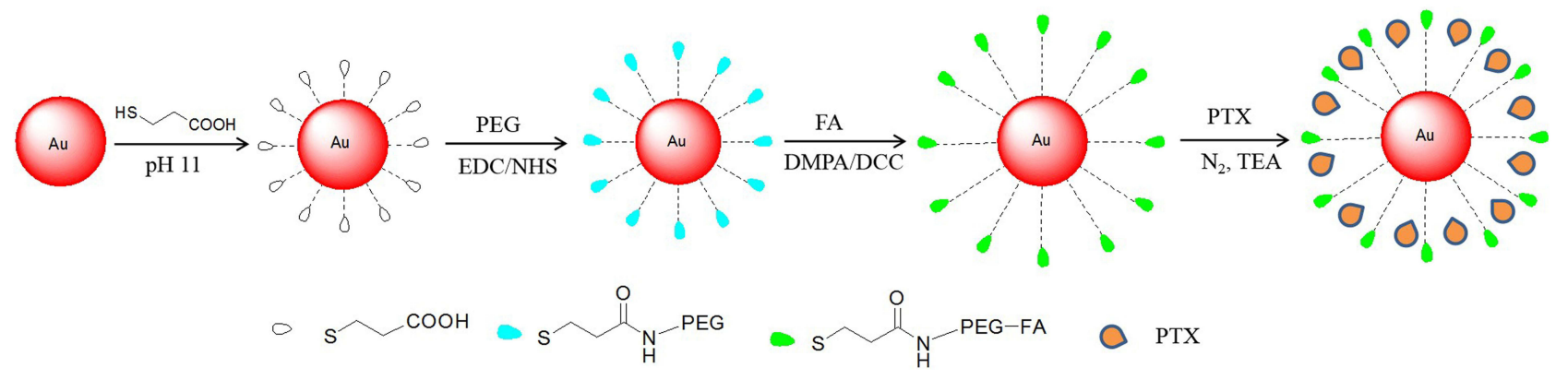

Scheme I Schematic representation of the synthesis of Au@MPA-PEG-FA-PTX. 

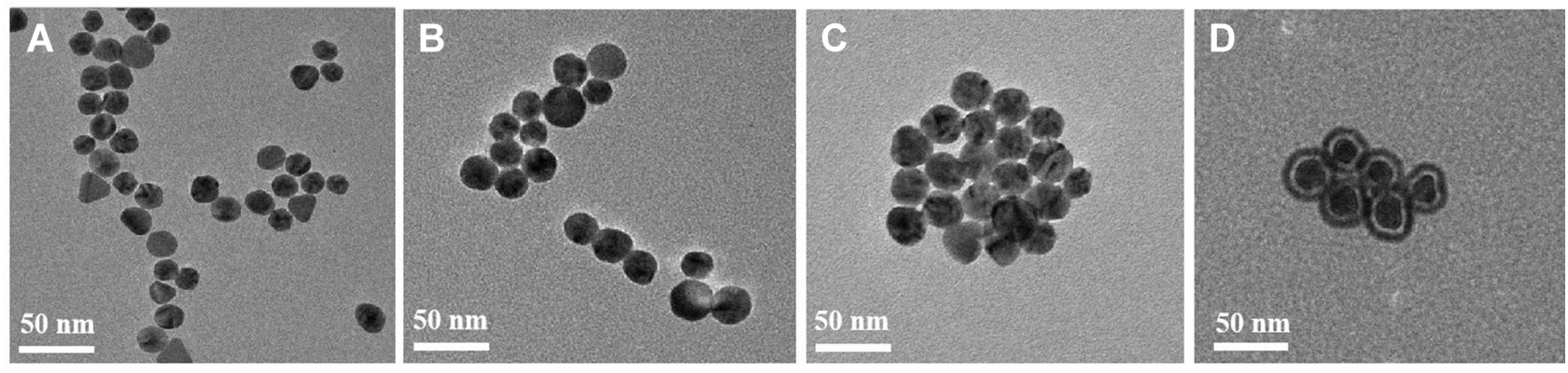

Figure I TEM images of AuNPs before and after modification. (A) Au@MPA; (B) Au@MPA-PEG; (C) Au@MPA-PEG-FA; (D) Au@MPA-PEG-FA-PTX.

Meanwhile, we also tested the optical properties of the AuNPs. UV-vis spectra shown in Figure S1 suggest that the unmodified AuNPs have an absorption peak at $520 \mathrm{~nm}$. However, surface modification of the AuNPs by FA and PEG led to a blue shift, showing an absorption peak at 680 $\mathrm{nm}$. Figure S2 shows the FTIR spectra of AuNPs. After the modification of AuNPs, a peak corresponding to the amide bond appeared at $1640 \mathrm{~cm}^{-1}$, while the other peak at $3100 \mathrm{~cm}^{-1}$ for vibrational stretching of the benzene ring indicated the successful loading of PTX.

\section{Drug Release in vitro}

The $\mathrm{pH}$ value is known to affect the drug release. The controlled release patterns and $\mathrm{pH}$ dependence of the rate of PTX release from Au@MPA-PEG-FA-PTX particles are illustrated by the cumulative drug release data presented in Figure 3. The release of PTX from Au@MPAPEG-FA-PTX nanoparticles was strongly affected by $\mathrm{pH}$ value. The PTX releases from Au@MPA-PEG-FA-PTX nanoparticles in the first $2 \mathrm{~h}$ were $30 \%$ and $50 \%$ of the total drug at $\mathrm{pH} 6.5$ and 5.0, respectively. And the rate of PTX release from Au@MPA-PEG-FA-PTX nanoparticles increased along with the extension of the stirring

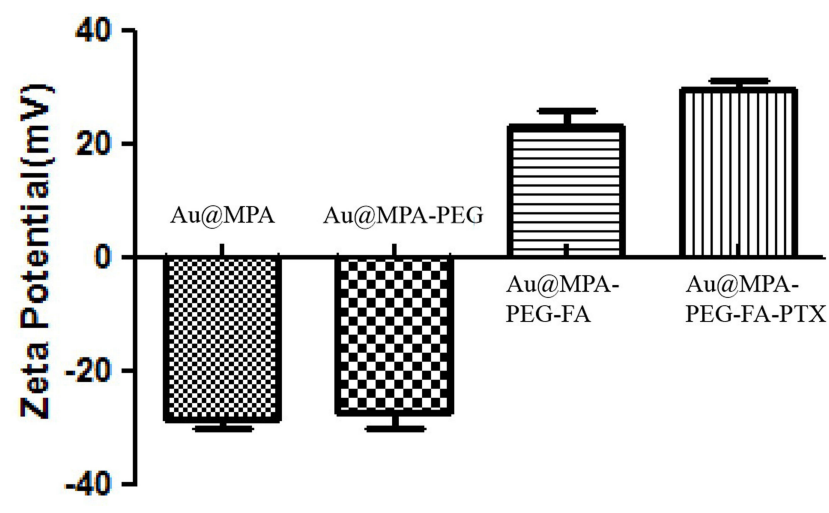

Figure 2 Change in Zeta value of AuNPs before and after modification. time. The rate of PTX release from Au@MPA-PEG-FAPTX nanoparticles increased at $6 \mathrm{~h}$ were $75 \%$ and $95 \%$ of the total drug at $\mathrm{pH} 6.5$ and 5.0, respectively. However, in intestinal-fluid-mimicking medium $(\mathrm{pH}$ 7.4), PTX release over $10 \mathrm{~h}$ was $62 \%$. This indicates that the $\mathrm{pH}$ value is the main key factor affecting PTX release fromAu@MPA-PEG-FA-PTX nanoparticles.

\section{Cytotoxicity Test}

Next, we performed the MTT assay to evaluate the cytotoxicity of AuNPs (Table S1). We found that the antitumor activity of the unmodified AuNPs was relatively low, and the $\mathrm{IC}_{50}$ decreased with an increase in the length of the modified chain. After PTX loading, the antitumor activity of AuNPs increased significantly. FA and PEG-modified Au@MPA-PEG-FAPTX showed high cytotoxicity against HCT-116, Hela and SMMC-7721 cells. Also, to check the specific targeting of the FA modified Au@MPA-PEG-FA-PTX, a competition was performed with free FA. We found that free FA reduced the cytotoxicity of $\mathrm{Au} @$ MPA-PEG-FA-PTX, indicating a receptor binding competition from FA, which reduced the binding of FA modified Au@MPA-PEG-FA-PTX. ${ }^{46,47}$

\section{Apoptosis Study}

Annexin V-FITC can be used to detect the early stages of apoptosis. $^{48,49}$ The apoptotic capability of Au@MPA-PEGFA-PTX was evaluated using annexin V-FITC staining by flow cytometry (Figure 4). We found that the apoptotic rates of 3, 5, 10, and $15 \mu \mathrm{g} / \mathrm{mL}$ AuNP@MPA-PEG-FA-PTX were $20.86 \%, 26.18 \%, 26.6 \%$, and $49.65 \%$, respectively. The apoptotic rate of $15 \mu \mathrm{g} / \mathrm{mL}$ PTX alone was $36.53 \%$, which is lower than that of drug-loaded AuNPs, indicating improved apoptotic activity of AuNP@MPA-PEG-FA-PTX.

Next, we examined the cell apoptosis using high content screening (HCS) by AO/EB staining. ${ }^{50}$ AO (green) gets inserted into the DNA despite an intact cell membrane, while EB (orange-red) can only be embedded 


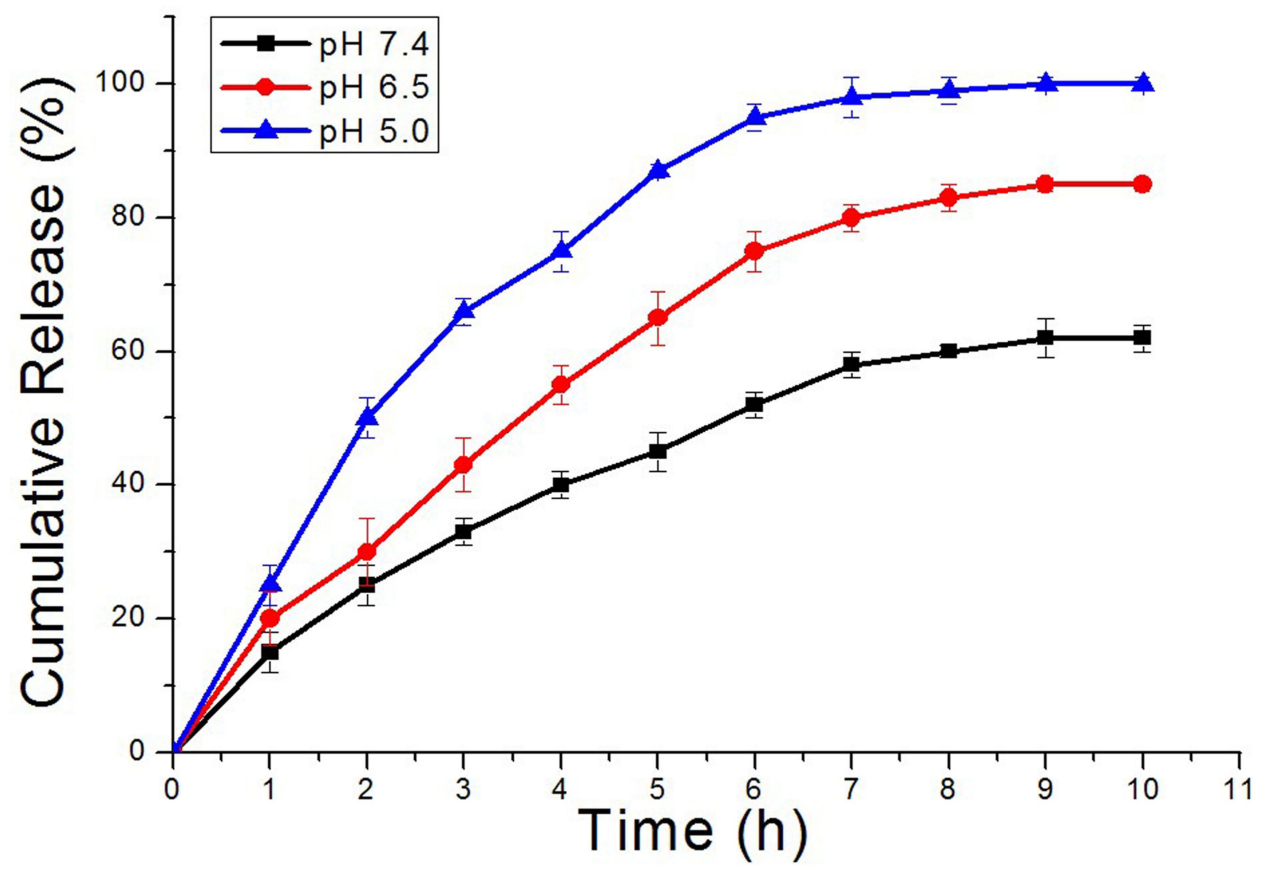

Figure 3 In vitro PTX release profiles from Au@MPA-PEG-FA-PTX with different loading contents in phosphate-buffered saline (PBS, pH 5.0, 6.5, and 7.4). The release was performed under gentle stirring and at $37^{\circ} \mathrm{C}$.

A

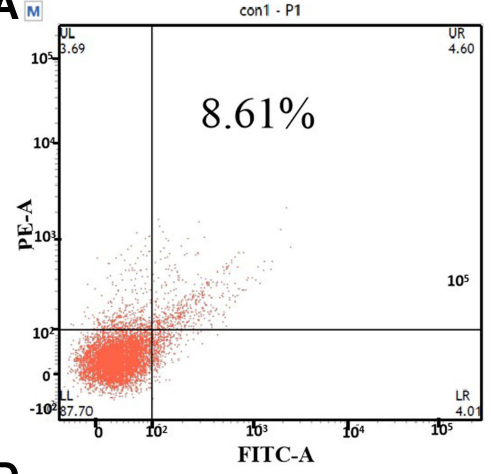

D

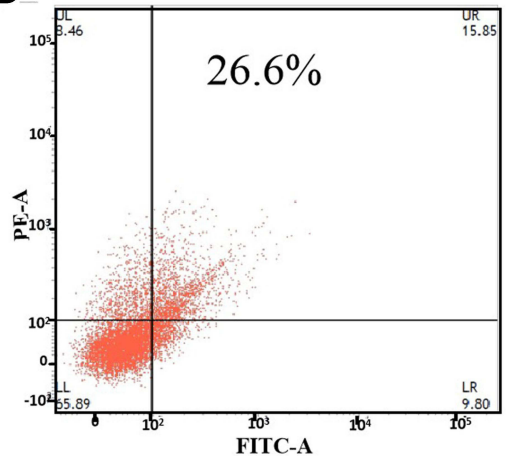

B

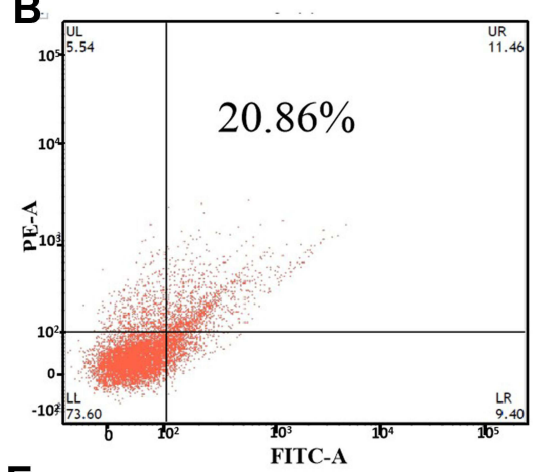

E

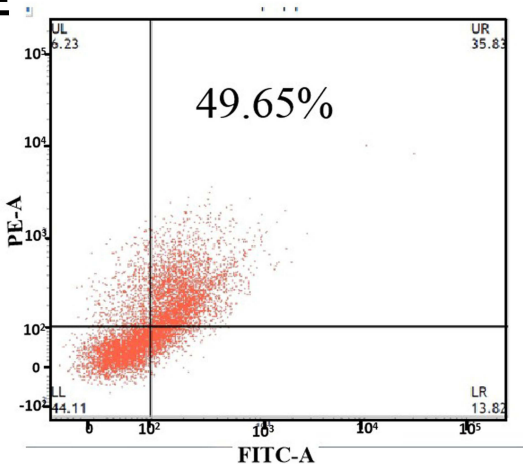

C

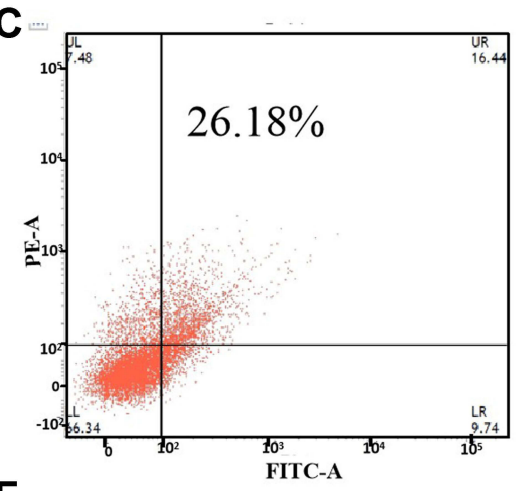

$\mathbf{F}$

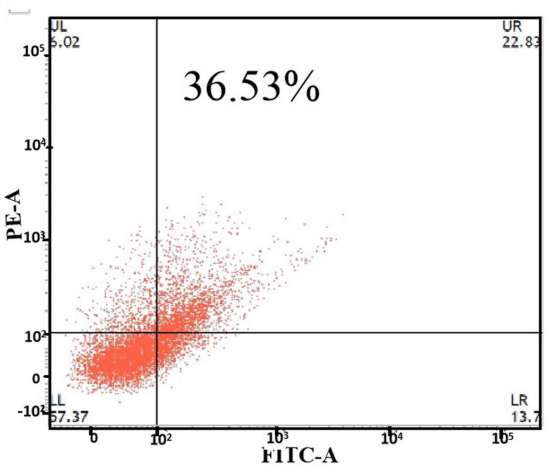

Figure 4 Apoptosis analysis in HeLa cells treated with Au@MPA-PEG-FA-PTX and PTX. (A) Control; (B-E) Au@MPA-PEG-FA-PTX (3, 5, I0, I5 $\mu g / m L) ;(F)$ PTX: I5 $\mu$ g/mL.

through the damaged (porous) cell membrane. As shown in Figure 5, in the high concentration Au@MPA-PEG-FAPTX group, a decrease in the green fluorescence, while an increase in the orange fluorescence indicated increased apoptosis and a damaged cell membrane. ${ }^{51}$ This was also consistent with flow cytometry results. 

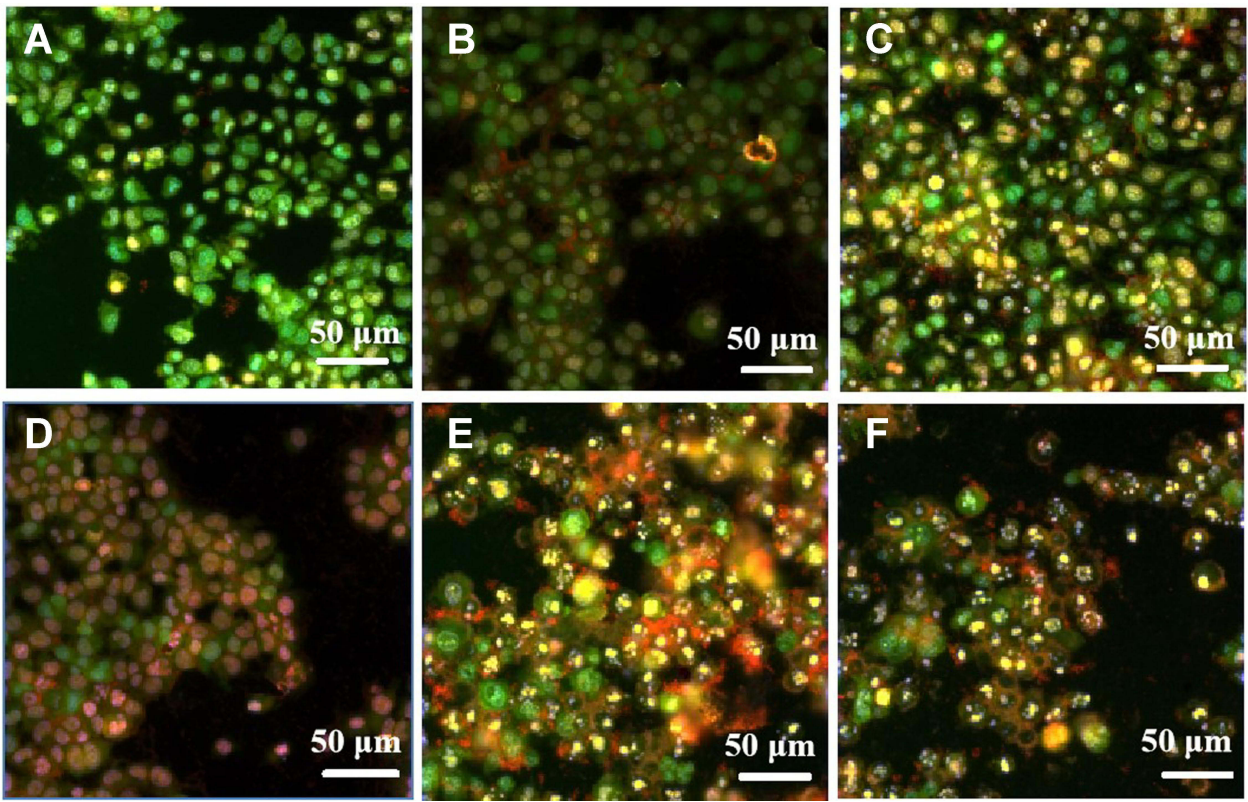

Figure 5 Apoptosis analysis in HeLa cells treated with Au@MPA-PEG-FA-PTX and PTX by AO/EB staining. (A) Control; (B-E) Au@MPA-PEG-FA-PTX (3, 5, I0, I5 $\mu$ / $\mathrm{mL}$ ); (F) PTX: $15 \mu \mathrm{g} / \mathrm{mL}$.

\section{Effect on Mitochondrial Membrane Potential (MMP)}

To examine the effect of Au@MPA-PEG-FA-PTX on mitochondrial dysfunction, HeLa cells were stained with JC-1 dye and analyzed by flow cytometry and HCS (Figure 6). We found that with an increase in
Au@MPA-PEG-FA-PTX concentration, the strong green fluorescence shifted to the right, and the red fluorescence shifted to the left, indicating a decrease in MMP. Figure 7 shows the Rh 123 and Hoechst 33342 stained cells. As the Au@MPA-PEG-FA-PTX concentration increased, the green fluorescence in the cells
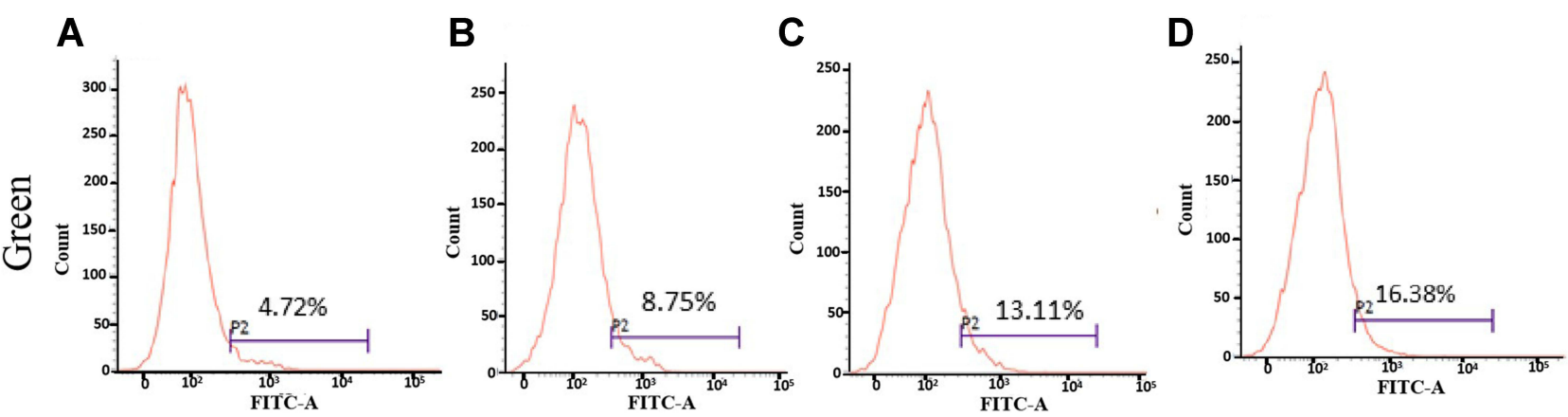

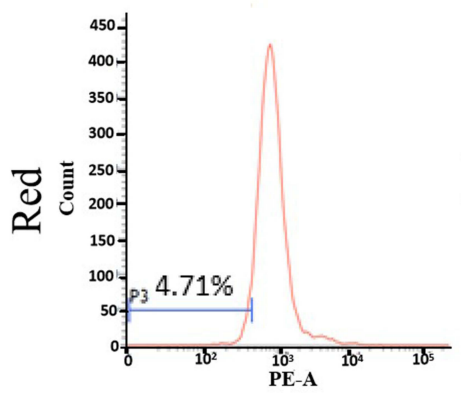

Control

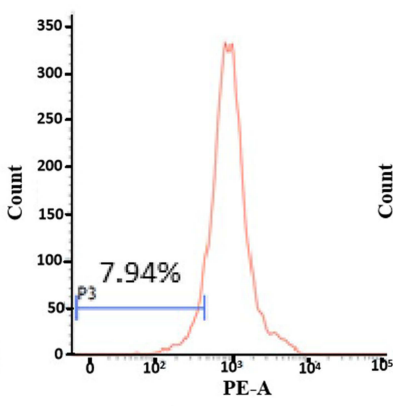

$3 \mu \mathrm{g} / \mathrm{mL}$

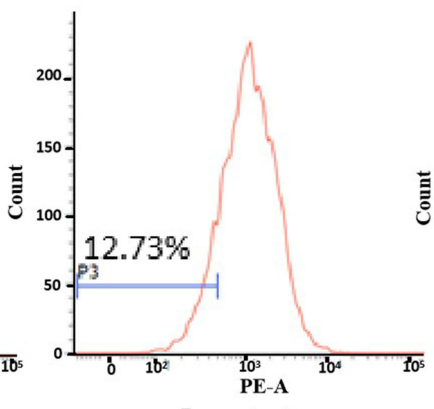

$5 \mu \mathrm{g} / \mathrm{mL}$

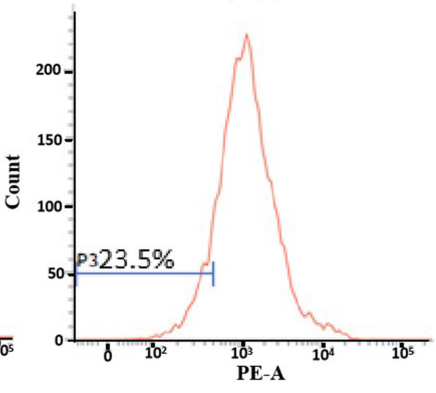

$15 \mu \mathrm{g} / \mathrm{mL}$

Figure 6 Flow cytometry analysis of Au@MPA-PEG-FA-PTX effect on MMP in HeLa cells. (A) Control, (B) $3 \mu \mathrm{g} / \mathrm{mL},(\mathbf{C}) 5 \mu \mathrm{g} / \mathrm{mL},(\mathbf{D}) \mathrm{I} 5 \mu \mathrm{g} / \mathrm{mL}$. 

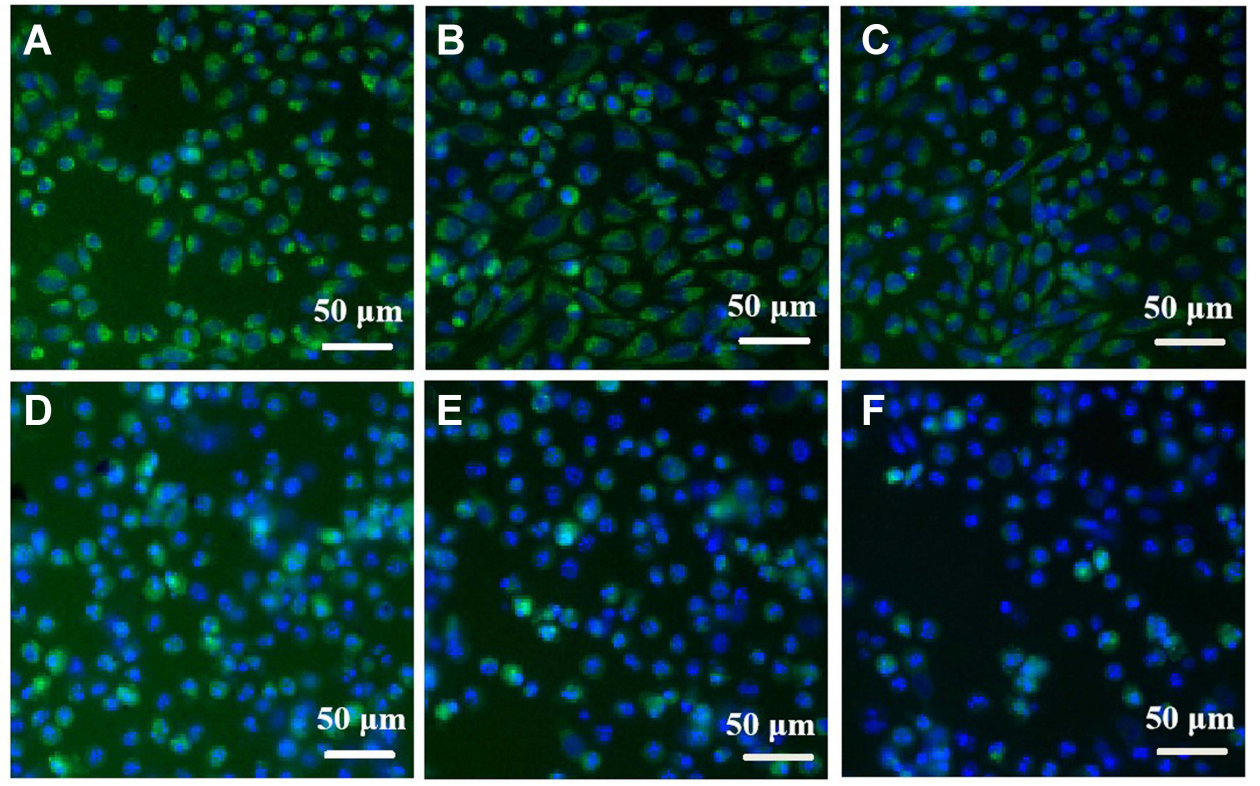

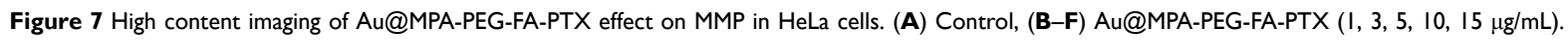

gradually decreased, while the cell morphology in the control and the low-concentration group remained relatively undamaged. However, Au@MPA-PEG-FA-PTX decreased the cell MMP, thereby inducing apoptosis.

\section{Effect on Intracellular Reactive Oxygen Species Changes Levels}

To investigate whether Au@MPA-PEG-FA-PTX induced mitochondrial membrane damage in the HeLa cells was due to the excessive accumulation of intracellular ROS, HCS imaging was employed with $\mathrm{H}_{2}$ DCF-DA reagent (Figure 8 ). We found that the intensity of green fluorescence $\left(\mathrm{H}_{2}\right.$ DCF-DA staining) in AuNPs drug-loading system-treated cells gradually increased with the concentration increase of AuNPs concentration, indicating elevated levels of intracellular ROS. ${ }^{52,53}$ This suggests that the Au@MPA-PEG-FA-PTX system promotes apoptosis via increasing the intracellular ROS amounts. $^{54}$

\section{The Antitumor Efficacy of Drug Delivery System in vivo}

To evaluate the antitumor efficacy of drug delivery system in vivo, Balb/c mice bearing CT-26 tumors with initial volumes of $200 \mathrm{~mm}^{3}$ were randomly divided into 3 groups with 5 mice in each group $(n=5)$. The mice were administered with physiological saline, free drug PTX (5 mg/ $\mathrm{kg}$ ), and Au@MPA-PEG-FA-PTX (5 mg/kg). Total seven doses were administered intravenously during the study period. On 15th days, all the mice were sacrificed and
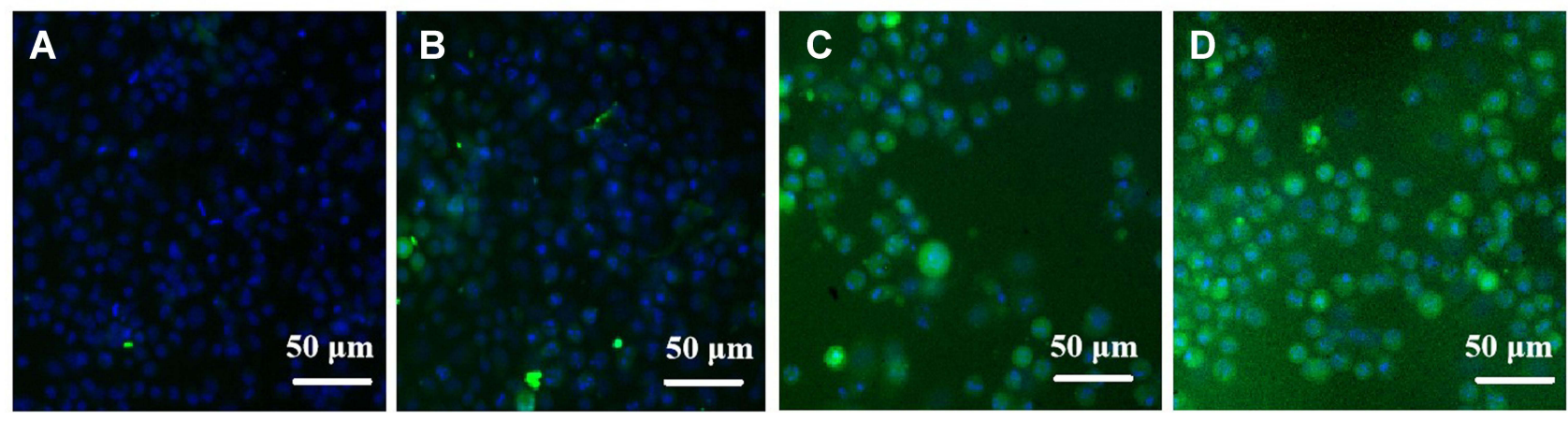

Figure 8 ROS accumulation by Au@MPA-PEG-FA-PTX. (A) Control; (B-D) Au@MPA-PEG-FA-PTX (3, 5, 15 g/mL). 

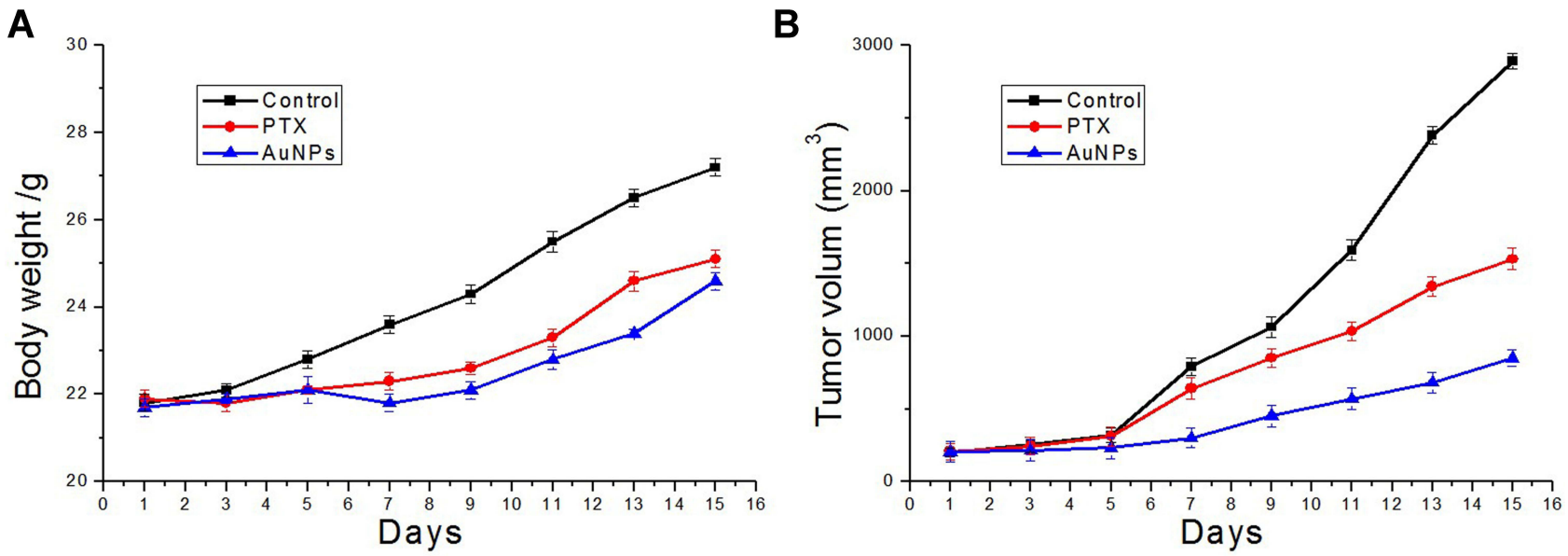

Figure 9 Anti-tumor efficacy of physiological saline, free PTX (5 mg/kg), and Au@MPA-PEG-FA-PTX (5 mg/kg) investigated following seven intravenous. (A) Body weight changes during the course of treatment; (B) changes in CT-26 tumor volumes.

the tumors as well as vital organs of each group were collected for weight measurements. During the treatment, physiological saline, free drug PTX and Au@MPA-PEGFA-PTX did not have an obvious effect on the mice body weight (Figure 9A). It was found that the size of the tumor in mice administered with $\mathrm{Au} @$ MPA-PEG-FA-PTX was only $850 \mathrm{~mm}^{3}$, which was much lower than that of control $\left(2890 \mathrm{~mm}^{3}\right)$ and PTX $\left(1532 \mathrm{~mm}^{3}\right)$ groups (Figure 9B). Altogether, these results suggest that the drug delivery system Au@MPA-PEG-FA-PTX displayed efficient antitumor efficacy in terms of inhibition of tumor growth, indicating its great potential for future biomedical applications.

\section{Conclusions}

In conclusion, we synthesized the FA and PEG-modified AuNPs drug delivery system Au@MPA-PEG-FA-PTX, which was characterized by a series of tests including TEM, Zeta potential, UV-vis, and FTIR. AuNPs showed good morphology. MTT assay showed that FA-modified PTX loaded AuNPs were more effective than PTX in isolation. Also, FA, PEG-modified Au@MPA-PEG-FAPTX showed very high activity against the HCT-116, Hela, and SMMC-7721 cells. Furthermore, competition with free FA revealed that Au@MPA-PEG-FA-PTX had good target selectivity. Analysis of apoptosis, MMP, and intracellular ROS levels showed that drug-loaded AuNPs induced apoptosis by reducing MMP and increasing levels of intracellular ROS. Thus, the AuNPs drug delivery system, with selective targeting of the folate-receptor overexpressing cancer cells, can be utilized as a potential theranostic agent as in cancer therapy.

\section{Abbreviations}

AuNPs, gold nanoparticles; PTX, paclitaxel; FA, folic acid; PEG, polyethylene glycol; FTIR, Fourier transform infrared spectroscopy; UV-Vis, Ultraviolet-visible spectroscopy; MTT, 3-(4,5-Dimethylthiazol-2-yl)-2,5-diphenyltetrazolium bromide; MMP, mitochondrial membrane potential; ROS, reactive oxygen species; MPA, mercaptopropionic acid; TEA, triethylamine; NHS, N-hydroxysuccinimide; MES, ethanesulfonic acid; EDC, ethylcarbodiimide hydrochloride; $\mathrm{PI}$, propidium iodide; $\mathrm{AO} / \mathrm{EB}$, acridine orange/ethidium bromide; $\mathrm{H}_{2} \mathrm{DCF}-\mathrm{DA}, 2^{\prime}, 7^{\prime}$-dichlorofluorescein diacetate; Rh123, rhodamine 123; JC-1, 5,5',6,6'-tetrachloro-1,1',3,3'tetraethyl-imidacarbocyanine iodide; TEM, Transmission electron microscope; FTIR, Fourier transform infrared; RT, room temperature; DMSO, dimethyl sulfoxide; DCC, dicyclohexylcarbodiimide; PBS, phosphate buffered saline; HCS, high content screening.

\section{Acknowledgments}

This work was supported by the National Natural Science Foundation of China (21501044), Foundation of Science and Technology Department of Henan Province (212102311018), a Major cultivation project of the Firstclass discipline of Henan University (2019YLZDJL09), and a Special Professor project of Henan University.

\section{Disclosure}

The authors report no conflicts of interest in this work. 


\section{References}

1. Hastman DA, Melinger JS, Aragones GL, et al. Femtosecond laser pulse excitation of DNA-labeled gold nanoparticles: establishing a quantitative local nanothermometer for biological applications. ACS Nano. 2020;14(7):8570-8583. doi:10.1021/ acsnano.0c02899

2. Wang Z, Wu X, Liu L, Xu L, Kuang H, Xu C. Rapid and sensitive detection of diclazuril in chicken samples using a gold nanoparticle-based lateral-flow strip. Food Chem. 2020;312:126116. doi:10.1016/j.foodchem.2019.126116

3. Du X-F, Zhu B-J, Cai Z-C, Wang C, Zhao M-X. Polyamine-modified gold nanoparticles readily adsorb on cell membranes for bioimaging. ACS Omega. 2019;4(18):17850-17856. doi:10.1021/acsomega.9b0 2579

4. Zhao M-X, Cai Z-C, Zhu B-J, Zhang Z-Q. The apoptosis effect on liver cancer cells of gold nanoparticles modified with lithocholic acid. Nanoscale Res Lett. 2018;13(1):304. doi:10.1186/s11671018-2653-8

5. Alkilany AM, Thompson LB, Boulos SP, Sisco PN, Murphy CJ. Gold nanorods: their potential for photothermal therapeutics and drug delivery, tempered by the complexity of their biological interactions. Adv Drug Deliv Rev. 2012;64(2):190-799. doi:10.1016/ j.addr.2011.03.005

6. Golchin K, Golchin J, Ghaderi S, et al. Gold nanoparticles applications: from artificial enzyme till drug delivery. Artif Cell Nanomed Biotechnol. 2018;46(2):150-254. doi:10.1080/ 21691401.2017.1305393

7. Shang L, Dong SJ, Nienhaus GU. Ultra-small fluorescent metal nanoclusters: synthesis and biological applications. Nano Today. 2011;6(4):401-418. doi:10.1016/j.nantod.2011.06.004

8. Zhang SX, Chen C, Xue C, et al. Ribbon of DNA lattice on gold nanoparticles for selective drug delivery to cancer cells. Angew Chem Int Ed. 2020;59(34):14584-14592. doi:10.1002/anie.202005624

9. Chen WT, Zhang FF, Ju YM, Hong J, Ding Y. Gold nanomaterial engineering for macrophage-mediated inflammation and tumor treatment. Adv Healthc Mater. 2020;10(5):2000818. doi:10.1002/ adhm. 202000818

10. Goddard ZR, Marin MJ, Russell DA, Searcey M. Active targeting of gold nanoparticles as cancer therapeutics. Chem Soc Rev. 2020;49 (23):8774-8789. doi:10.1039/D0CS01121E

11. D'Acunto M, Cioni P, Gabellieri E, Presciuttini G. Exploiting gold nanoparticles for diagnosis and cancer treatments. Nanotechnology. 2021;32(19):192001. doi:10.1088/1361-6528/abe1ed

12. Li L-S, Ren B, Yang X, Cai Z-C, Zhao X-J, Zhao M-X. Hyaluronic acid-modified and doxorubicin-loaded gold nanoparticles and evaluation of their bioactivity. Pharmaceuticals. 2021;14(2):101. doi:10. 3390/ph14020101

13. Chuang CC, Chen YN, Wang YY, et al. Stem cell-based delivery of gold/chlorin e6 nanocomplexes for combined photothermal and photodynamic therapy. ACS Appl Mater Interfaces. 2020;12 (27):30021-30030. doi:10.1021/acsami.0c03446

14. Yang KK, Liu YJ, Wang Y, et al. Enzyme-induced in vivo assembly of gold nanoparticles for imaging-guided synergistic chemo-photothermal therapy of tumor. Biomaterials. 2019;223:119460. doi:10.1016/j. biomaterials.2019.119460

15. Haghighi FH, Binaymotlagh R, Mirahmadi-Zare SZ, Hadadzadeh H. Aptamer/magnetic nanoparticles decorated with fluorescent gold nanoclusters for selective detection and collection of human promyelocytic leukemia (HL-60) cells from a mixture. Nanotechnology. 2020;31(2):025605. doi:10.1088/1361-6528/ab484a

16. Muhammad N, Zhao H, Song WJ, et al. Silver nanoparticles functionalized Paclitaxel nanocrystals enhance overall anti-cancer effect on human cancer cells. Nanotechnology. 2021;32(8):085105. doi:10. 1088/1361-6528/abcacb
17. Bhattacharyya J, Bellucci JJ, Weitzhandler I, et al. A Paclitaxel-loaded recombinant polypeptide nanoparticle outperforms Abraxane in multiple murine cancer models. Nat Commun. 2015;6 (12):79-86. doi:10.1038/ncomms8939

18. Li LL, Chen D, Zheng K, et al. Enhanced antitumor efficacy and imaging application of photosensitizer-formulated paclitaxel. ACS Appl Mater Interfaces. 2020;12(4):4221-4230. doi:10.1021/acsami. $9 \mathrm{~b} 18396$

19. Wang J, Zhang WL, Wu T, et al. Photodynamic antitumor activity of aggregation-induced emission luminogens as chemosensitizers for paclitaxel by concurrent induction of apoptosis and autophagic cell death. Mater Chem Front. 2021;5(8):3448-3457. doi:10.1039/ d1qm00089f

20. Xiong XY, Tao L, Qin X, et al. Novel folated pluronic/poly(lactic acid) nanoparticles for targeted delivery of paclitaxel. RSC $A d v$. 2016;6(58):52729-52738. doi:10.1039/C6RA09271C

21. Xu J, Ong HX, Traini D, et al. Paclitaxel-eluting silicone airway stent for preventing granulation tissue growth and lung cancer relapse in central airway pathologies. Expert Opin Drug Deliv. 2020;17 (11):1631-1645. doi:10.1080/17425247.2020.1811224

22. Chavez JD, Keller A, Zhou B, Tian R, Bruce JE. Cellular interactome dynamics during paclitaxel treatment. Cell Rep. 2019;29 (8):2371-2385. doi:10.1016/j.celrep.2019.10.063

23. Hirota K, Hristova T, Mitova V, et al. Polyphosphoester-based paclitaxel complexes: biological evaluation. Anticancer Res. 2016;36 (4):1320-1613.

24. Ding Y, Zhou Y-Y, Chen H, et al. The performance of thiol-terminated PEG-paclitaxel-conjugated gold nanoparticles. Biomaterials. 2013;34 (38):10217-10227. doi:10.1016/j.biomaterials.2013.09.008

25. Zhang X-Q, Xu X, Lam R, Giljohann D, Ho D, Mirkin CA. Strategy for increasing drug solubility and efficacy through covalent attachment to polyvalent DNA-nanoparticle conjugates. ACS Nano. 2011;5 (9):6962-6970. doi:10.1021/nn201446c

26. Chen Y, Li N, Yang Y, Liu Y. A dual targeting cyclodextrin/gold nanoparticle conjugate as a scaffold for solubilization and delivery of paclitaxel. $R S C A d v$. 2015;5(12):8938-8941. doi:10.1039/C4RA13135E

27. Danhier F, Feron O, Preat V. To exploit the tumor microenvironment: passive and active tumor targeting of nanocarriers for anti-cancer drug delivery. J Control Release. 2010;148(2):135-146. doi:10.10 16/j.jconrel.2010.08.027

28. Attia MF, Anton N, Wallyn J, Omran Z, Vandamme TF. An overview of active and passive targeting strategies to improve the nanocarriers efficiency to tumour sites. J Pharm Pharmacol. 2019;71 (8):1185-1198. doi:10.1111/jphp.13098

29. Singh AV, Ansari MHD, Laux P, Luch A. Micro-nanorobots: important considerations when developing novel drug delivery platforms. Expert Opin Drug Deliv. 2019;16(11):1259-1275. doi:10.1080/ 17425247.2019.1676228

30. Singh AV, Ansari MHD, Dayan CB, et al. Multifunctional magnetic hairbot for untethered osteogenesis, ultrasound contrast imaging and drug delivery. Biomaterials. 2019;219:119394. doi:10.1016/j. biomaterials.2019.119394

31. Mou Q, Ma Y, Zhu X, Yan D. A small molecule nanodrug consisting of amphiphilic targeting ligand-chemotherapy drug conjugate for targeted cancer therapy. $J$ Control Release. 2016;230:34-44. doi:10.1016/j.jconrel.2016.03.037

32. Li Y, Lin JY, Cai Z, et al. Tumor microenvironment-activated self-recognizing nanodrug through directly tailored assembly of small-molecules for targeted synergistic chemotherapy. $J$ Control Release. 2020;321(10):222-235. doi:10.1016/j.jconrel.2020.02.025

33. Scaranti M, Cojocaru E, Banerjee S, Banerji U. Exploiting the folate receptor alpha in oncology. Nat Rev Clin Oncol. 2020;17(6):349-359. doi:10.1038/s41571-020-0339-5

34. Fernandez M, Javaid F, Chudasama V. Advances in targeting the folate receptor in the treatment/imaging of cancers. Chem Sci. 2018;9(4):790-810. doi:10.1039/C7SC04004K 
35. Zhong YA, Meng FH, Deng C, Zhong ZY. Ligand-directed active tumor-targeting polymeric nanoparticles for cancer chemotherapy. Biomacromolecules. 2014;15(6):1955-1969. doi:10.1021/bm5003009

36. Zhang S, Chan KH, Prud'homme RK, Link AJ. Synthesis and evaluation of clickable block copolymers for targeted nanoparticle drug delivery. Mol Pharm. 2012;9(8):2228-2236. doi:10.1021/mp3000748

37. Chen X, Shi Z, Tong R, et al. Derivative of epigallocatechin-3-gallatea encapsulated in ZIF-8 with polyethylene glycol-folic acid modification for target and $\mathrm{pH}$-responsive drug release in anticancer research. ACS Biomater Sci Eng. 2018;4(12):4183-4192. doi:10. 1021/acsbiomaterials. 8 b00840

38. Yao Q, Choi JH, Dai Z, et al. Improving tumor specificity and anticancer activity of dasatinib by dual-targeted polymeric micelles. ACS Appl Mater Interfaces. 2017;9(42):36642-36648. doi:10.1021/ acsami.7b12233

39. Jang EH, Shim MK, Kim GL, Kim SH, Kang H, Kim JH. Hypoxiaresponsive folic acid conjugated glycol chitosan nanoparticle for enhanced tumor targeting treatment. Int $J$ Pharm. 2020;580 (30):119237. doi:10.1016/j.ijpharm.2020.119237

40. Zhao J, Du J, Wang J, et al. Folic acid and poly(ethylene glycol) decorated paclitaxel nanocrystals exhibit enhanced stability and breast cancer-targeting capability. ACS Appl Mater Interfaces. 2021;13(12):14577-14586. doi:10.1021/acsami.1c00184

41. Huang P, Xu C, Lin J, et al. Folic acid-conjugated graphene oxide loaded with photosensitizers for targeting photodynamic therapy. Theranostics. 2011;1:240-250. doi:10.7150/thno/v01p0240

42. Singh AV, Batuwangala M, Mundra R, et al. Biomineralized anisotropic gold microplate-macrophage interactions reveal frustrated phagocytosis-like phenomenon: a novel paclitaxel drug delivery vehicle. ACS Appl Mater Interfaces. 2014;6(16):14679-14689. doi:10.1021/am504051b

43. Baek HS, Yoo JY, Rah DK, et al. Evaluation of the extraction method for the cytotoxicity testing of latex gloves. Yonsei Med J. 2005;46 (4):579-583. doi:10.3349/ymj.2005.46.4.579

44. Erdogar N, Esendagli G, Nielsen TT, Sen M, Oner L, Bilensoy E. Design and optimization of novel paclitaxel-loaded folate-conjugated amphiphilic cyclodextrin nanoparticles. Int J Pharm. 2016;509(12):375-390. doi:10.1016/j.ijpharm.2016.05.040

45. Wang ZH, Chen SH, Hu CY, Cui DX, Jia NQ. An enhanced impedance cytosensor based on folate conjugated-polyethyleniminecarbon nanotubes for tumor targeting. Electrochem Commun. 2013;29:4-7. doi:10.1016/j.elecom.2012.12.025
46. Saadat M, Zahednezhad F, Zakeri-Milani P, Heidari HR Shahbazi-Mojarrad J, Valizadeh H. Drug targeting strategies based on charge dependent uptake of nanoparticles into cancer cells. J Pharm Pharmacol. 2019;22(1):191-220. doi:10.18433/ jpps30318

47. Stella B, Arpicco S, Peracchia MT, et al. Design of folic acid-conjugated nanoparticles for drug targeting. J Pharm Sci. 2000;89(11):1452-1464. doi:10.1002/1520-6017(200011)89:11<14 52::AID-JPS8>3.0.CO;2-P

48. van Engeland M, Nieland LJ, Ramaekers FC, Schutte B, Reutelingsperger CP. Annexin V-affinity assay: a review on an apoptosis detection system based on phosphatidylserine exposure Cytometry. 1998;31(1):1-9. doi:10.1002/(SICI)1097-0320(1998010 1)31:1<1::AID-CYTO1>3.0.CO;2-R

49. Singh AV, Maharjan R-S, Kanase A, et al. Machine-learning-based approach to decode the influence of nanomaterial properties on their interaction with cells. ACS Appl Mater Interfaces. 2021;13 (1):1943-1955. doi:10.1021/acsami.0c18470

50. Wu X, Liu PC, Liu R, Dual WX. Dual AO/EB staining to detect apoptosis in osteosarcoma cells compared with flow cytometry. Med Sci Monit Basic Res. 2015;21:15-20. doi:10.12659/ MSMBR.893327

51. Alabi OA, Bakare AA, Filippin-Monteiro FB, Sierra JA, CreczynskiPasa TB. Electronic waste leachate-mediated DNA fragmentation and cell death by apoptosis in mouse fibroblast (NIH/3T3) cell line. Ecotoxicol Environ Saf. 2013;94:87-93. doi:10.1016/j.ecoenv. 2013.05 .004

52. Singh AV, Jahnke T, Wang S, et al. Anisotropic gold nanostructures: optimization via in silico modeling for hyperthermia. ACS Appl Nano Mater. 2018;1(11):6205-6216. doi:10.1021/acsanm.8b01406

53. Lindberg GCJ, Longoni A, Lim KS, et al. Intact vitreous humor as a potential extracellular matrix hydrogel for cartilage tissue engineering applications. Acta Biomater. 2019;85:117-130. doi:10.1016/j. actbio.2018.12.022

54. Gourlay CW, Ayscough KR. The actin cytoskeleton: a key regulator of apoptosis and ageing? Nat Rev Mol Cell Biol. 2005;6(7):583-589. doi: $10.1038 / \mathrm{nrm} 1682$
International Journal of Nanomedicine

\section{Publish your work in this journal}

The International Journal of Nanomedicine is an international, peerreviewed journal focusing on the application of nanotechnology in diagnostics, therapeutics, and drug delivery systems throughout the biomedical field. This journal is indexed on PubMed Central, MedLine, CAS, SciSearch ${ }^{\circledR}$, Current Contents ${ }^{\circledR} /$ Clinical Medicine,
Journal Citation Reports/Science Edition, EMBase, Scopus and the Elsevier Bibliographic databases. The manuscript management system is completely online and includes a very quick and fair peer-review system, which is all easy to use. Visit http://www.dovepress.com/ testimonials.php to read real quotes from published authors. 